\title{
Evaluation of MLPA as a comprehensive molecular cytogenetic tool to detect cytogenetic markers of chronic lymphocytic leukemia in Egyptian patients
}

Ola M. Eid ${ }^{1}$, Rania M. A. Abdel Kader ${ }^{1 *}$, Lamiaa A. Fathalla², Amany H. Abdelrahman³, Ahmed Rabea ${ }^{4}$, Rana Mahrous ${ }^{1}$ and Maha M. Eid ${ }^{1}$

\begin{abstract}
Background: Chronic lymphocytic leukemia (CLL) is the most common form of adult leukemia. This disease is genetically heterogeneous, and approximately $85 \%$ of patients with CLL harbor chromosomal aberrations that are considered effective prognostic biomarkers. The most frequent aberrations include deletions in 13q14, followed by trisomy 12, and deletions in 11q22.3 and 17p13 (TP53). Currently, fluorescence in situ hybridization (FISH) is the most widely used molecular cytogenetic technique to detect these aberrations. However, FISH is laborious, timeconsuming, expensive, and has a low throughput. In contrast, multiplex ligation-dependent probe amplification (MLPA) is a reliable, cost-effective, and relatively rapid technique that can be used as a first-line screening tool and complement with FISH analysis. This study aimed to evaluate the contributions of MLPA as a routine standalone screening platform for recurrent chromosomal aberrations in CLL in comparison to other procedures. Thirty patients with CLL were screened for the most common genomic aberrations using MLPA with SALSA MLPA probemix P038B1 CLL and FISH.
\end{abstract}

Results: In 24 of the 30 cases (80\%), the MLPA and FISH results were concordant. Discordant results were attributed to a low percentage of mosaicism. Moreover, the MLPA probemix contains probes that target other genomic areas known to be linked to CLL in addition to those targeting common recurrent CLL aberrations.

Conclusions: The usage of MLPA as the first screening platform followed by FISH technique for only the negative cases is the most appropriate approach for CLL diagnosis and prognosis.

Keywords: Chronic lymphocytic leukemia (CLL), Chromosomal aberrations, Multiplex ligation-dependent probe amplification (MLPA), Fluorescence in situ hybridization (FISH)

\section{Background}

Chronic lymphocytic leukemia (CLL) is the most common form of adult leukemia in western countries, accounting for $30 \%$ of all leukemia cases. However, it is infrequent in the Eastern world. In Upper Egypt, CLL accounts for around $11.3 \%$ of all leukemia cases. This

\footnotetext{
* Correspondence: Rania_m_heggy@hotmail.com

${ }^{1}$ Human Cytogenetics Department, Human Genetics and Genome Research Division, National Research Centre, Bohouth Street, 12311 Dokki, Cairo, Egypt Full list of author information is available at the end of the article
}

hematopoietic neoplasm arises from B-lymphocytes in the peripheral blood, bone marrow, and/or lymph nodes $[1,2]$. Moreover, CLL is a genetically heterogeneous disease, and the clinical course may range from months to decades. Approximately $85 \%$ of CLL patients harbor chromosomal aberrations, which are considered effective prognostic biomarkers. The most frequent aberrations involve deletions in 13q14 (50-60\%), which are associated with a good prognosis. The next most frequent aberration is trisomy $12(12-25 \%)$, which is associated with 
intermediate prognosis, followed by 11q22.3 (ATM; 10$20 \%$ ) and $17 \mathrm{p} 13$ (TP53; 5-10\%) deletions, which are associated with a poor prognosis. These aberrations are important prognostic biomarkers for treatment decisionmaking [3].

Currently, fluorescence in situ hybridization (FISH) is the most widespread molecular cytogenetic technique used to detect genetic abnormalities in CLL [4]. However, FISH cannot detect small or intragenic deletions. Moreover, FISH is a laborious, time-consuming, expensive, and low-throughput procedure relative to other molecular genetic procedures used to detect common aberrations. Several other chromosomal aberrations in CLL have been detected using different techniques. However, these aberrations are not usually analyzed in clinical practice [5].

Multiplex ligation-dependent probe amplification (MLPA) was first introduced in 2002 [6]. This multiplex PCR technique can detect abnormal copy numbers in up to 50 different genomic DNA or RNA sequences and can differentiate sequences differing in only one nucleotide. Up to 96 samples can be tested simultaneously by MPLA, and the turn-around time is within $24 \mathrm{~h}$. Consequently, MLPA has considerably increased the detection rates of various genetic disorders [7]. MLPA has also been applied successfully to the detection of copy number abnormalities in various malignant hematopoietic disorders, such as CLL [8]. MLPA is a reliable, costeffective technique and is more rapid than FISH. Although MLPA cannot detect low-level mosaicism, it remains useful as a first-line screening tool and complement with FISH analysis [9]. The commercially available SALSA MLPA probemix P038 was designed specifically for CLL screening and permits the concurrent evaluation of various risk-linked genomic targets. This kit contains probes for 10q (PTEN), 11q (ATM, RDX, PPP2R1B, CADM1), chromosome 12, 13q14. (RB1, DLEU1/2/7, KCNRG, MIR15A), 14q, 17p (TP53), and chromosome 19.

This study aimed to evaluate the contributions of MLPA as a routine standalone screening platform for recurrent chromosomal aberrations in CLL in comparison to other procedures such as FISH.

\section{Methods}

This study was conducted at the National Research Centre, Egypt, and was approved by its Medical Ethical Committee. Informed written consent was obtained from the study participants. Thirty CLL patients (16 males, 14 females) were included in this study. The average age at the time of sampling was 65 years (range, 3688 years). All participants attended the National Cancer Institute, Cairo University, Egypt. The diagnosis of CLL was established according to the World Health
Organization classification of hematolymphoid tumors [10]. CLL was diagnosed by the presence of at least 5000 monoclonal B-lymphocytes/ $\mu$ with a CLL immune phenotype in the peripheral blood (PB) for at least 3 months. Typically, CLL lymphocytes are small and mature-looking, with scanty cytoplasm and a dense nucleus containing partially aggregated chromatin. PB samples were collected on heparin to enable blood culture and on K2-EDTA in a vacutainer tube to allow DNA extraction.

\section{FISH analysis}

Peripheral heparinized blood samples were cultured without mitogens and incubated at $37^{\circ} \mathrm{C}$ for $24 \mathrm{~h}$. Cell harvesting and slide preparation were performed using the standard conventional cytogenetic methods.

FISH analysis was performed according to the manufacturer's instructions and Pinkel et al. [11], using FISH probes for the most common genomic aberrations associated with CLL, including trisomy 12 and deletions at the 13q14, 11q22, and 17p13 loci. All FISH probes were commercially available (Cytocell, UK). The slides were examined using a suitable filter set on an optimally performing fluorescence microscope with an applied imaging system. A total of 200 interphase cells were examined per patient.

\section{MLPA assay}

DNA was extracted from the PB lymphocytes of all 30 cases and reference samples (one reference sample per seven patient samples, with a minimum of three references per test) using the QIAamp DNA Mini Kit (Germany) according to the manufacturer's instructions. The quality and quantity of the DNA samples were determined using a NanoDrop spectrophotometer.

The MLPA assay was performed using SALSA MLPA probemix P038-B1 CLL according to the manufacturer's instructions (MRC-Holland, Netherlands). This probemix comprises multiple probes specific for chromosomal regions and genes associated with recurrent copy number aberrations in B-lymphocyte CLL, including 10q23.31 (PTEN), 11q 22 (ATM, RDX, PPP2R1B, CADM1), chromosome 12, 13q14 (RB1, DLEU1/2/7, KCNRG, MIR15A), 14q, 17p (TP53), and chromosome 19. Moreover, the P038 probemix contains three probes to detect the NOTCH1 7541-7542delCT, SF3B1 K700E, and MYD88 L265P mutations, which only produce a signal when the precise mutation is present. The assay kit included SD009 sample DNA as a positive control for the mutation-specific probes and data binning in the fragment analysis.

The DNA denaturation and overnight MLPA probemix hybridization steps were followed by probe ligation and amplification on the following day. The amplified 
products were separated using an ABI 3500 Genetic Analyzer (Applied Biosystems, USA). The results were interpreted using the Coffalyser.Net software (MRC, Holland). Ratios of $<0.75,0.75-1.30$, and $>1.3$ were considered to indicate deletion, normal, and duplication, respectively.

\section{Results}

Samples from 30 patients with CLL were studied. The FISH and MLPA results are summarized in Table 1.

FISH detected aberrations in 21 cases (70\%), whereas no abnormalities were detected in nine cases (30\%). The most common defect was trisomy 12, which was present in 12 patients (40\%). A 13q14 deletion was detected in 10 cases, while an 11q22 deletion was observed in four cases, and a $17 \mathrm{p} 13$ deletion was detected in three cases (Table 2, Fig. 1).

MLPA detected aberrations in 20 cases (66.7\%) and no abnormalities in the remaining 10 cases (33.3\%). The most common abnormality was trisomy 12 , which was present in nine cases (30\%). A 13q14 deletion was detected in nine cases, while the $R B 1$ gene was not included in the deleted area in four cases. The $17 \mathrm{p} 13$ deletion and 11q22 deletion were detected in three cases each, and the 14q deletion and trisomy 19 were observed in one patient each (Table 2). NOTCH1 75417542delCT, SF3B1 K700E, and MYD88 L265P mutations were not detected in any of the patients (Fig. 2).

\section{Discussion}

Many authors have recommended the use of MLPA as an initial diagnostic test $[12,13]$. In this study, we aimed to determine the usefulness of the MLPA probemix P038-B1 as a routine standalone screening platform for the detection of clinically relevant chromosome abnormalities in CLL.

Samples from six of the 30 studied patients $(20 \%)$ yielded discordant MLPA and FISH results. Two cases had a 14q deletion and trisomy 19 respectively, which were not evaluated by FISH in this study. Five cases harbored abnormalities that were identified by FISH but not by MLPA. So, MLPA results were consistent with the FISH results in 24 of 30 patients (80\%). Fabris et al. [8] detected a 95\% concordance rate between MLPA and FISH results in CLL. The discordant results in these cases may be related to a low level of mosaicism. However, the definition of low mosaicism, or the level at which abnormalities could not be detected by MLPA, has differed between studies and remains controversial. For example, the reported mosaicism thresholds have ranged from $36 \%$ in a study by $\mathrm{Al}$ Zaabi et al. [9] to $20 \%$ in a study by Abdool et al. [14]. However, false-negative MLPA results were reported in samples with an aberrant cell percentage $<25 \% \quad[15,16]$. In our study,
Table 1 Summary of the aberrations detected by MLPA and $\mathrm{FISH}$

\begin{tabular}{|c|c|c|}
\hline & FISH Mosaic (\%) & MLPA \\
\hline \multirow[t]{2}{*}{1} & $11 q$ del (53\%) & $11 q$ del \\
\hline & Tri 12 (83\%) & Tri 12 \\
\hline \multirow[t]{2}{*}{$2^{a}$} & Tri $12(4 \%)$ & - \\
\hline & $13 q$ del (29\%) & $13 q$ del \\
\hline 3 & No Abn & No Abn \\
\hline 4 & No Abn & No Abn \\
\hline 5 & $13 q$ del (30\%) & $13 q$ del \\
\hline 6 & No Abn & No Abn \\
\hline 7 & $13 q$ del (73\%) & $13 q$ del \\
\hline 8 & No Abn & No Abn \\
\hline $9^{a}$ & Tri 12 (5\%) & No Abn \\
\hline \multirow[t]{3}{*}{$10^{\mathrm{a}}$} & Tri 12 (59\%) & Tri 12 \\
\hline & $13 q$ del (16\%) & - \\
\hline & - & Tri 19 \\
\hline 11 & $13 q$ del $(76 \%)$ & $13 q$ del \\
\hline 12 & $17 p$ del (87\%) & $17 p$ del \\
\hline 13 & No Abn & No Abn \\
\hline \multirow[t]{2}{*}{14} & Tri 12 (72\%) & Tri 12 \\
\hline & $17 p$ del (74\%) & $17 p$ del \\
\hline \multirow[t]{2}{*}{$15^{\mathrm{a}}$} & Tri 12 (9\%) & - \\
\hline & $13 q$ del (79\%) & $13 q$ del \\
\hline 16 & Tri 12 (85\%) & Tri 12 \\
\hline 17 & $17 p$ del (80\%) & $17 p$ del \\
\hline \multirow[t]{2}{*}{$18^{\mathrm{a}}$} & $11 q$ del $(6 \%)$ & - \\
\hline & Tri 12 (48\%) & Tri 12 \\
\hline 19 & No Abn & No Abn \\
\hline 20 & $13 q$ del (48\%) & $13 q$ del \\
\hline 21 & No Abn & No Abn \\
\hline \multirow[t]{2}{*}{22} & $11 q$ del (87\%) & $11 \mathrm{q}$ del \\
\hline & $13 q$ del (55\%) & $13 q$ del \\
\hline 23 & No Abn & No Abn \\
\hline 24 & $13 q$ del (28\%) & $13 q$ del \\
\hline 25 & Tri 12 (27\%) & Tri 12 \\
\hline 26 & Tri 12 (60\%) & Tri 12 \\
\hline 27 & No Abn & No Abn \\
\hline \multirow[t]{2}{*}{28} & $11 q$ del (60\%) & $11 q$ del \\
\hline & Tri 12 (50\%) & Tri 12 \\
\hline \multirow[t]{2}{*}{$29^{\mathrm{a}}$} & Tri 12 (90\%) & Tri 12 \\
\hline & - & $14 q$ del \\
\hline 30 & $13 q$ del (68\%) & $13 q$ del \\
\hline
\end{tabular}

No Abn no abnormalities detected

The discordant results of MLPA and FISH are marked with asterisk ${ }^{a}$ 
Table 2 Frequencies of the abnormalities detected by MLPA and FISH

\begin{tabular}{lllll}
\hline Abnormality & Genes & Detected by MLPA & Detected by FISH & Result \\
\hline 11q deletion & ATM, RDX, PPP2R1B, CADM1 & 3 & 4 & Disconcordant \\
Trisomy $\mathbf{1 2}$ & CD27, STAT6, HMGA2, PAH, IGF1 & 9 & 12 & Disconcordant \\
13q14 deletion & DLEU2, KCNRG, DLEU1, RB1, KCNRG, ATP7B & 9 & 10 & Disconcordant \\
14q deletion & AKT1, MTA1, K1AA0125 & 1 & - & Disconcordant \\
17p deletion & TP53 & 3 & 3 & Concordant \\
Trisomy $\mathbf{1 9}$ & LDLR, CDKN2D, AKT2, MIR498 & 1 & - & Disconcordant \\
\hline
\end{tabular}

abnormalities could be detected by MLPA in a sample containing $27 \%$ mosaicism.

Interstitial deletion at $13 \mathrm{q} 14$ is the most common chromosomal aberration in CLL and is detected in approximately $50 \%$ of cases. The deletion of $13 \mathrm{q}$ as the sole abnormality is strongly associated with a favorable disease outcome and a better prognosis. Studies suggest that the clinical course of CLL is accelerated in patients with a large 13q14 deletion that includes the $R B 1$ gene. Moreover, reciprocal translocations involving 13q14 [t(13q)] and many different chromosomes have been reported. However, the lack of recurrent other abnormalities suggests that the consequence of these translocations is possibly due to the loss of a tumor suppressor gene rather than the generation of a fusion gene [17]. In our study, five of the nine cases in which a 13q deletion was detected by MLPA were affected by large deletions that included the $R B 1$ gene.
With sufficient accumulated genotoxic damage, CLL cells are directed to undergo cell cycle arrest or apoptosis. ATM and TP53 genes govern the cellular response to DNA damage through the ATM-CHK2-p53 signaling pathway. Alterations of these genes lead to genomic instability and chemoresistance and are associated with adverse prognosis with significantly shorter overall survival [18-20].

11q deletion, which causes a loss of the ATM gene at $11 \mathrm{q} 22.3$, is detected in $25 \%$ of CLL cases. This is the most frequently detected unfavorable genetic anomaly in patients with CLL. Larger 11q deletions also occur and may affect the tumor suppressor genes $P P P 2 R 1 B$, $C A D M$, and $R D X[21,22]$. In our study, all patients in whom MLPA detected an 11q deletion were affected by large deletions that included these tumor suppressor genes.

While 17p deletion causes a loss of the tumor suppressor gene TP53 at 17p13.1 and is associated with a rapid

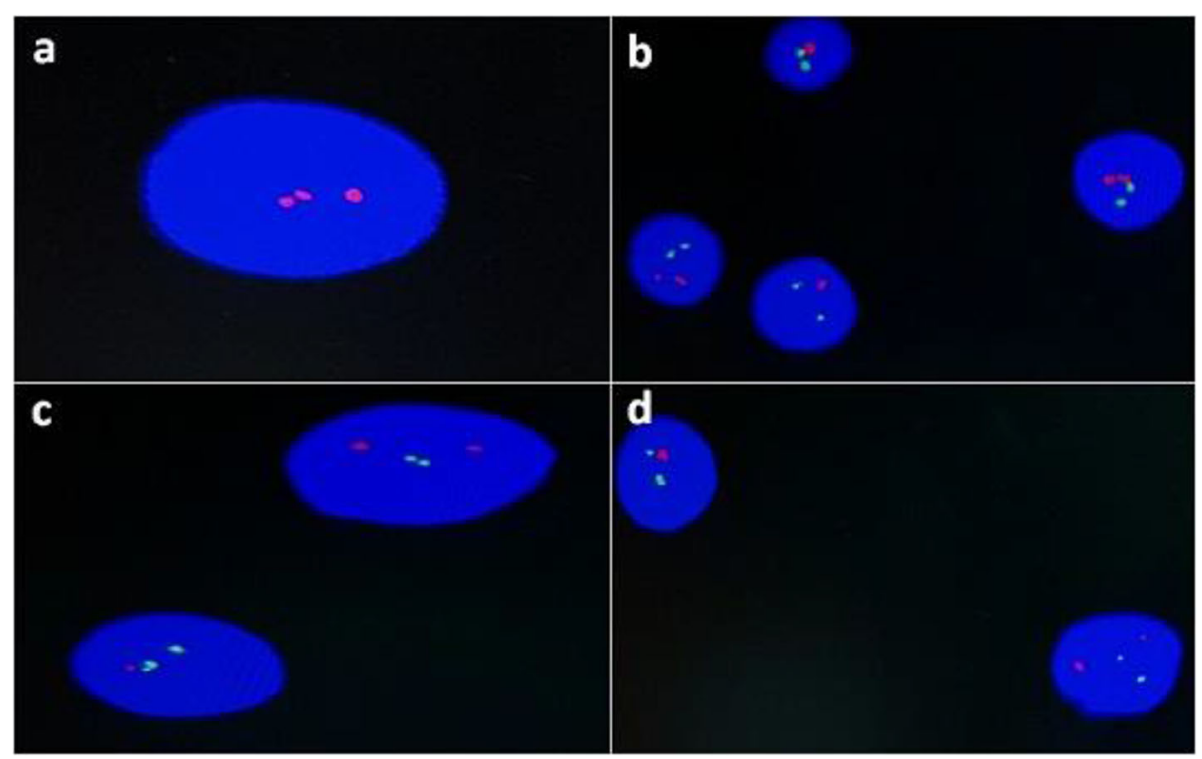

Fig. $1 \mathrm{FISH}$ analysis showing a trisomy 12 denoted by the presence of three red signals, $\mathbf{b}$ mosaic positive $11 \mathrm{q} 23$ del denoted by the presence of one red signal and two control green signals for centromere 11, c mosaic positive 13q14 del denoted by the presence of one red signal and two control green signals for the $13 q 34$ region, and $\mathbf{d}$ mosaic positive 17 p13 del denoted by the presence of one red signal and two control green signals for centromere 17 


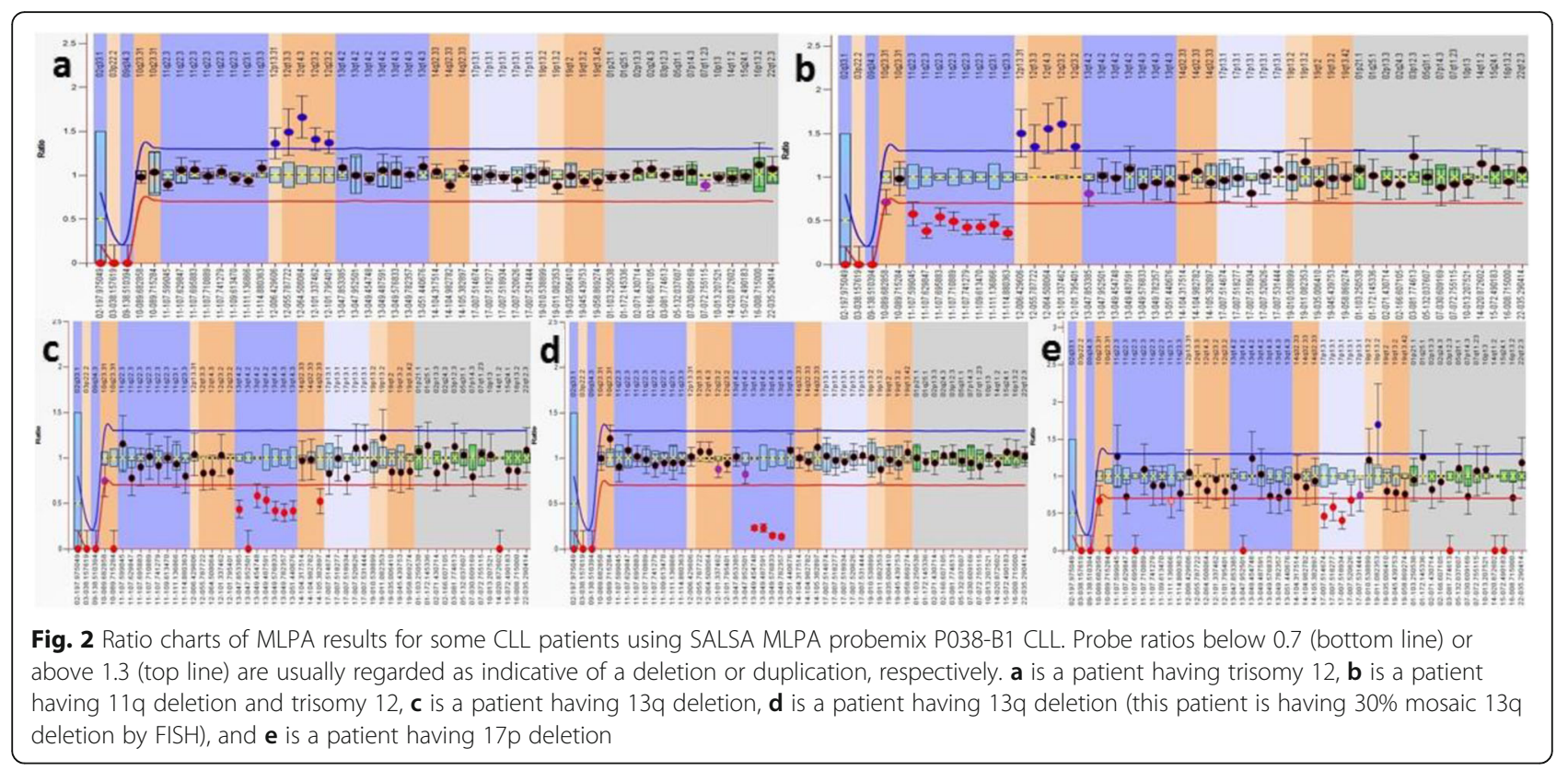

disease progression, poor outcome, drug resistance, and reduced survival duration, in the literature, the incidence of $17 \mathrm{p}$ deletion varies widely from 3.4 to $16.8 \%$ [23, 24]. In our study, both MLPA and FISH detected $17 \mathrm{p}$ deletions in three cases (10\%).

Trisomy 12 is the third most common chromosomal aberration detected in patients with CLL. This abnormality is identified in $10-20 \%$ of patients [25]. In our study, MLPA and FISH detected trisomy 12 in nine and 12 cases, respectively. This discordance was attributed to the previously discussed low level of mosaicism in three cases.

In addition to four probes that target common recurrent CLL aberrations, the MLPA probemix contains probes that target other genomic areas known to be linked to CLL. These areas, namely, 10q (PTEN), 14q, and chromosome 19, are not targeted by the FISH probe panel. PTEN is a tumor suppressor gene. PTEN is impaired in several types of cancers and plays an important role in CLL pathogenesis. Studies have described defective PTEN function in CLL, either through gene mutation/deletion or promoter methylation [26, 27]. While $14 \mathrm{q}$ deletions are rare recurrent alterations in CLL frequently associated with trisomy $12,14 \mathrm{q}$ deletions are associated with a short time to treatment. 14q deletions seem to have an adverse prognostic impact when associated with trisomy 12 [28]. Also, trisomy 19 has been detected infrequently in CLL cases and is usually associated with trisomy 12 [29]. In our study, no abnormalities were detected in the 10q (PTEN) region. Only one case harbored a $14 \mathrm{q}$ deletion, and one case harbored trisomy 19, and both cases were having associated trisomy 12.
Moreover, the P038 probemix includes probes to detect three mutations: NOTCH1 7541-7542delCT, SF3B1 K700E, and MYD88 L265P. These mutations are recently identified as CLL disease parameters. The presence of these mutations is associated with at least one unfavorable prognostic marker [30-33]. However, these mutations were not detected in any of our patients.

\section{Conclusions}

From our study, both assays have comparable capabilities to detect CLL aberrations. MLPA technique is disadvantaged by its inability to detect targeted abnormalities in a sample with a low level of mosaicism. However, the restricted number of regions that can be evaluated by FISH is considered to be disadvantageous. MLPA is more cost-efficient than FISH and encompasses a broader range of target gene loci. Nevertheless, we recommend the usage of MLPA as the first screening platform followed by FISH technique for only the negative cases as the most appropriate approach for CLL diagnosis and prognosis.

\section{Abbreviations \\ CLL: Chronic lymphocytic leukemia; DNA: Deoxyribonucleic acid; FISH: Fluorescence in situ hybridization; MLPA: Multiplex ligation-dependent probe amplification; PB: Peripheral blood; PCR: Polymerase chain reaction; RNA: Ribonucleic acid}

\section{Acknowledgements}

We would like to express our gratitude to the National Research Centre, Egypt, for giving us the chance to accomplish this study with the help of its updated equipment and instrumentation.

\section{Authors' contributions}

OE: providing the idea of this research, preparing the design of the research, participated in conducting the laboratory work, interpretation of the data, and preparing the paper for submission and final approval of the version to 
be published. RA: participated in conducting the laboratory work and preparing the paper for submission. LF: participated in conducting the laboratory work and preparing the paper for submission. AA: participated in conducting the laboratory work and preparing the paper for submission. AR: participated in clinical evaluation of the patients and preparing the paper for submission. RM: participated in conducting the laboratory work and preparing the paper for submission. ME: participated in performing the laboratory work and preparing the paper for submission. The authors have read and approved the final manuscript.

\section{Funding}

The MLPA assay part of this research was supported by In-house Research

Project grant, grant number: AR111303, National Research Centre, Egypt.

\section{Availability of data and materials}

Data and material are available upon request.

\section{Declarations}

\section{Ethics approval and consent to participate}

The study was approved by the ethical committee of the National Research Centre (18-047), which is in accordance with the ethical standards of the Declaration of Helsinki. All participants gave informed written consent before their inclusion in the study.

\section{Consent for publication}

Not applicable.

\section{Competing interests}

The authors declare that they have no competing interests.

\section{Author details}

${ }^{1}$ Human Cytogenetics Department, Human Genetics and Genome Research Division, National Research Centre, Bohouth Street, 12311 Dokki, Cairo, Egypt. ${ }^{2}$ Clinical Pathology Department, National Cancer Institute, Cairo University, Cairo, Egypt. ${ }^{3}$ Clinical Pathology Department, National Research Centre, Cairo, Egypt. ${ }^{4}$ Oncology Department, National Cancer Institute, Cairo University, Cairo, Egypt.

\section{Received: 10 February 2021 Accepted: 14 June 2021}

Published online: 28 June 2021

\section{References}

1. Hussein S, Mohamed D, Hafez R (2019) Risk factors of hematological malignancies in Upper Egypt: a case-control study. Egypt J Internal Med 31(2):171-177. https://doi.org/10.4103/ejim.ejim_81_18

2. Mosaad ZE, Mohamed ZA, Abdelazeem MA, Hafez R, Hussein S, Elaiw MA (2019) Impact of CD39 expression on CD4+ T lymphocytes and 6 q deletion on outcome of patients with chronic lymphocytic leukemia. Hematol Oncol Stem Cell Ther 12(1):26-31. https://doi.org/10.1016/j.hemonc.2018.09.002 Epub 2018 Oct 11. PMID: 30336122

3. Ayaz A, Tepeli E, Sari l, Cetin O, Eser M, Dogu H, Bagci G (2014) Contribution of MLPA to routine testing to detect the prognostic chromosomal abnormalities in chronic lymphocytic leukemia. Gene Ther Mol Biol 16:1-9

4. Rahimi H, Sadeghian MH, Keramati MR, Jafarian AH, Shakeri S, Shams SF et al (2017) Cytogenetic abnormalities with interphase FISH method and clinical manifestation in chronic lymphocytic leukemia patients in NorthEast of Iran. Int J Hematol Oncol Stem Cell Res 11(3):217-224

5. Durmaz AA, Karaca E, Demkow U, Toruner G, Schoumans J, Cogulu O (2015) Evolution of genetic techniques: past, present, and beyond. Biomed Res Int 2015:461524

6. Schouten JP, McElgunn CJ, Waaijer R, Zwijnenburg D, Diepvens F, Pals G (2002) Relative quantification of 40 nucleic acid sequences by multiplex ligation-dependent probe amplification. Nucleic Acids Res 30(12):e57. https://doi.org/10.1093/nar/gnf056

7. Stuppia L, Antonucci I, Palka G, Gatta V (2012) Use of the MLPA assay in the molecular diagnosis of gene copy number alterations in human genetic diseases. Int J Mol Sci 13(3):3245-3276. https://doi.org/10.3390/ijms13033245

8. Fabris S, Scarciolla O, Morabito F, Cifarelli RA, Dininno C, Cutrona G, Matis S, Recchia AG, Gentile M, Ciceri G, Ferrarini M, Ciancio A, Mannarella C, Neri A, Fragasso A (2011) Multiplex ligation-dependent probe amplification and fluorescence in situ hybridization to detect chromosomal abnormalities in chronic lymphocytic leukemia: a comparative study. Genes Chromosomes Cancer 50(9):726-734. https://doi.org/10.1002/gcc.20894

9. Al Zaabi EA, Fernandez LA, Sadek IA, Riddell DC, Greer WL (2010) Multiplex ligation-dependent probe amplification versus multiprobe fluorescence in situ hybridization to detect genomic aberrations in chronic lymphocytic leukemia: a tertiary center experience. J MolDiagn 12(2):197-203

10. Muller-Hermelink HK, Montserrat E, Catovsky D, Campo E, Harris NL, Stein H (2008) Chronic lymphocytic leukemia/small lymphocytic lymphoma. In: World Health Organization. Classification of tumours of haematopoietic and lymphoid tissues, 4th edn. IARC Press, Lyon

11. Pinkel D, Gray JW, Trask B, van den Engh G, Fuscoe J, van Dekken H. Cytogenetic analysis by in situ hybridization with fluorescently labeled nucleic acid probes. Cold Spring HarbSymp Quant Biol. 1986;51Pt 1:151-157. doi:https://doi.org/10.1101/sqb.1986.051.01.018.

12. Hömig-Hölzel C, Savola S (2012) Multiplex ligation-dependent probe amplification (MLPA) in tumor diagnostics and prognostics. Diagn Mol Pathol 21(4):189-206

13. Alhourani E, Rincic M, Othman MA, Pohle B, Schlie C, Glaser A, Liehr T. Comprehensive chronic lymphocytic leukemia diagnostics by combined multiplex ligation dependent probe amplification (MLPA) and interphase fluorescence in situ hybridization (iFISH). Mol Cytogenet. 2014;19;7(1):79.

14. Abdool A, Donahue AC, Wohlgemuth JG, Yeh CH (2010) Detection, analysis and clinical validation of chromosomal aberrations by multiplex ligationdependent probe amplification in chronic leukemia. PLoS One 5(10):e15407. https://doi.org/10.1371/journal.pone.0015407

15. Coll-Mulet L, Santidrián AF, Cosialls AM, Iglesias-Serret D, de Frias M, Grau J, Menoyo A, González-Barca E, Pons G, Domingo A, Gil J (2008) Multiplex ligation-dependent probe amplification for detection of genomic alterations in chronic lymphocytic leukaemia. Br J Haematol 142(5):793-801. https://doi. org/10.1111/j.1365-2141.2008.07268.x

16. Véronèse $L$, Tournilhac $O$, Combes $P$, Prie N, Pierre-Eymard E, Guièze R, Veyrat-Masson R, Bay JO, Vago P, Tchirkov A (2013) Contribution of MLPA to routine diagnostic testing of recurrent genomic aberrations in chronic lymphocytic leukemia. Cancer Genet 206(1-2):19-25. https://doi.org/10.1016/ j.cancergen.2012.12.002

17. Puiggros A, Venturas M, Salido M, Blanco G, Fernandez-Rodriguez C, Collado R, Valiente A, Ruiz-Xivillé N, Carrió A, Ortuño FJ, Luño E, Calasanz MJ, Ardanaz MT, Piñán MÁ, Talavera E, González MT, Ortega M, Marugán I, Ferrer A, Gimeno E, Bellosillo B, Delgado J, Hernández JÁ, Hernández-Rivas JM, Espinet B; GrupoCooperativoEspañol de CitogenéticaHematológica (GCEC GH); GrupoEspañol de LeucemiaLinfáticaCrónica (GELLC). Interstitial 13q14 deletions detected in the karyotype and translocations with concomitant deletion at 13 q14 in chronic lymphocytic leukemia: different genetic mechanisms but equivalent poorer clinical outcome. Genes Chromosomes Cancer. 2014;53(9):788-97. doi: https://doi.org/10.1002/gcc.22188. Epub 2014 Jun 10. PMID: 24915757.

18. Knittel G, Liedgens P, Reinhardt HC. Targeting ATM-deficient CLL through interference with DNA repair pathways. Front Genet. 2015;6:207. doi: https:// doi.org/10.3389/fgene.2015.00207. PMID: 26113859; PMCID: PMC4461826.

19. Kwok M, Davies N, Agathanggelou A, Smith E, Oldreive C, Petermann E, Stewart G, Brown J, Lau A, Pratt G, Parry H, Taylor M, Moss P, Hillmen P, Stankovic T (2016) ATR inhibition induces synthetic lethality and overcomes chemoresistance in TP53- or ATM-defective chronic lymphocytic leukemia cells. Blood. 127(5):582-595. https://doi.org/10.1182/blood-2015-05-644872 Epub 2015 Nov 12 PMID: 26563132

20. Chauffaille MLLF, Zalcberg I, Barreto WG, Bendit I. Detection of somatic TP53 mutations and $17 p$ deletions in patients with chronic lymphocytic leukemia: a review of the current methods. Hematol Transfus Cell Ther. 2020;42(3): 261-268. doi: https://doi.org/10.1016/j.htct.2020.05.005. Epub 2020 Jun 25. PMID: 32660851; PMCID: PMC7417461.

21. Gunn SR, Hibbard MK, Ismail SH, Lowery-Nordberg M, Mellink CH, Bahler DW et al (2009) Atypical 11q deletions identified by array CGH may be missed by FISH panels for prognostic markers in chronic lymphocytic leukemia. Leukemia 23(5):1011-1017. https://doi.org/10.1038/leu.2008.393

22. Guarini A, Marinelli M, Tavolaro S, Bellacchio E, Magliozzi M, Chiaretti S, de Propris MS, Peragine N, Santangelo S, Paoloni F, Nanni M, del Giudice I, Mauro FR, Torrente I, Foa R (2012) ATM gene alterations in chronic lymphocytic leukemia patients induce a distinct gene expression profile and predict disease progression. Haematologica 97(1):47-55. https://doi.org/1 0.3324/haematol.2011.049270 
23. Buccheri V, Barreto WG, Fogliatto LM, Capra M, Marchiani M, Rocha V (2018) Prognostic and therapeutic stratification in CLL: focus on 17p deletion and p53 mutation. Ann Hematol 97(12):2269-2278. https://doi.org/10.1007/s002 77-018-3503-6 Epub 2018 Oct 12 PMID: 30315344

24. Bagacean C, Tempescul A, Ternant D, Banet A, Douet-Guilbert N, Bordron A, Bendaoud B, Saad H, Zdrenghea M, Berthou C, Paintaud G, Renaudineau Y. $17 p$ deletion strongly influences rituximab elimination in chronic lymphocytic leukemia. J Immunother Cancer. 2019;7(1):22. doi: https://doi. org/10.1186/s40425-019-0509-0. PMID: 30696487; PMCID: PMC6352369.

25. Dőhner $H$, Stilgenbauer $S$, Benner $A$, Leupolt E, Krőber A, Bullinger $L$ et al (2000) Genomic aberrations and survival in chronic lymphocytic leukemia. N Engl J Med 343(26):1910-1916. https://doi.org/10.1056/NEJM200012283432 602

26. Zou ZJ, Zhang R, Fan L, Wang L, Fang C, Zhang LN, Yang S, Li YY, Li JY, Xu W (2013) Low expression level of phosphatase and tensin homolog deleted on chromosome ten predicts poor prognosis in chronic lymphocytic leukemia. Leuk Lymphoma 54(6):1159-1164. https://doi.org/10.3109/104281 94.2012.733880 Epub 2012 Oct 16 PMID: 23013295

27. Bernardi R, Ghia P. Reactivating nuclear PTEN to treat CLL. Oncotarget. 2017; 8(22):35486-35487. doi: https://doi.org/10.18632/oncotarget.17543. PMID: 28473667; PMCID: PMC5482590.

28. Cosson A, Chapiro E, Belhouachi N, Cung HA, Keren B, Damm F, Algrin C, Lefebvre C, Fert-Ferrer S, Luquet I, Gachard N, Mugneret F, Terre C, Collonge-Rame MA, Michaux L, Rafdord-Weiss I, Talmant P, Veronese L, Nadal N, Struski S, Barin C, Helias C, Lafage M, Lippert E, Auger N, Eclache V, Roos-Weil D, Leblond V, Settegrana C, Maloum K, Davi F, Merle-Beral H, Lesty C, Nguyen-Khac F; Groupe Francophone de CytogénétiqueHématologique. 14q deletions are associated with trisomy 12, NOTCH1 mutations and unmutated IGHV genes in chronic lymphocytic leukemia and small lymphocytic lymphoma. Genes Chromosomes Cancer. 2014;53(8):657-66. doi: https://doi.org/10.1002/gcc.22176. Epub 2014 Apr 12. PMID: 24729385.

29. Sellmann L, Gesk S, Walter C, Ritgen M, Harder L, Martín-Subero Jl, Schroers R, Siemer D, Nückel H, Dyer MJS, Dührsen U, Siebert R, Dürig J, Küppers R (2007) Trisomy 19 is associated with trisomy 12 and mutated IGHV genes in B-chronic lymphocytic leukaemia. Br J Haematol 138(2):217-220. https://doi. org/10.1111/j.1365-2141.2007.06636.x

30. Wang L, Lawrence MS, Wan Y, Stojanov P, Sougnez C, Stevenson K, Werner L, Sivachenko A, DeLuca DS, Zhang L, Zhang W, Vartanov AR, Fernandes SM, Goldstein NR, Folco EG, Cibulskis K, Tesar B, Sievers QL, Shefler E, Gabriel S, Hacohen N, Reed R, Meyerson M, Golub TR, Lander ES, Neuberg D, Brown $J R$, Getz G, Wu CJ. SF3B1 and other novel cancer genes in chronic lymphocytic leukemia. N Engl J Med. 2011;365(26):2497-506. doi: https://doi. org/10.1056/NEJMoa1109016. Epub 2011 Dec 12. PMID: 22150006; PMCID: PMC3685413.

31. Sutton LA, Ljungström V, Mansouri L, Young E, Cortese D, Navrkalova V, Malcikova J, Muggen AF, Trbusek M, Panagiotidis P, Davi F, Belessi C, Langerak AW, Ghia P, Pospisilova S, Stamatopoulos K, Rosenquist R. Targeted next-generation sequencing in chronic lymphocytic leukemia: a high-throughput yet tailored approach will facilitate implementation in a clinical setting. Haematologica. 2015;100(3):370-6. doi: https://doi.org/1 0.3324/haematol.2014.109777. Epub 2014 Dec 5. PMID: 25480502; PMCID: PMC4349276

32. Vollbrecht C, Mairinger FD, Koitzsch U, Peifer M, Koenig K, Heukamp LC, Crispatzu G, Wilden L, Kreuzer KA, Hallek M, Odenthal M, Herling CD, Buettner R. Comprehensive analysis of disease-related genes in chronic lymphocytic leukemia by multiplex PCR-based next generation sequencing. PLoS One. 2015;10(6):e0129544. doi: https://doi.org/10.1371/journal.pone.012 9544. PMID: 26053404: PMCID: PMC4459702.

33. Srinivasan VK, Naseem S, Varma N, Lad DP, Malhotra P. Genomic alterations in chronic lymphocytic leukemia and their correlation with clinicohematological parameters and disease progression. Blood Res. 2020;55(3): 131-138. doi: https://doi.org/10.5045/br.2020.2020080. PMID: 32747613; PMCI D: PMC7536571.

\section{Publisher's Note}

Springer Nature remains neutral with regard to jurisdictional claims in published maps and institutional affiliations.

\section{Submit your manuscript to a SpringerOpen ${ }^{\circ}$ journal and benefit from:}

- Convenient online submission

- Rigorous peer review

- Open access: articles freely available online

- High visibility within the field

- Retaining the copyright to your article

Submit your next manuscript at $\boldsymbol{\sim}$ springeropen.com 